\title{
Adenosarcoma of the cervix uteri
}

INSERM

\section{Source}

INSERM. (1999). Orphanet: an online rare disease and orphan drug data base.

Adenosarcoma of the cervix uteri. ORPHA:213792

Adenosarcoma of the cervix uteri is a rare subtype of malignant mixed epithelial and mesenchymal tumor composed of benign or mildly atypical glandular elements and a surrounding low-grade malignant stroma, often containing heterologous elements, such as areas of sex-cord-like or smooth muscle differentiation. It usually presents with vag inal bleeding or discharge, lower abdominal pain and/or a cervical mass or polyp. The tumor may arise from pre-existing endometriosis and patients may have a history of recurrent cervical polyps. 